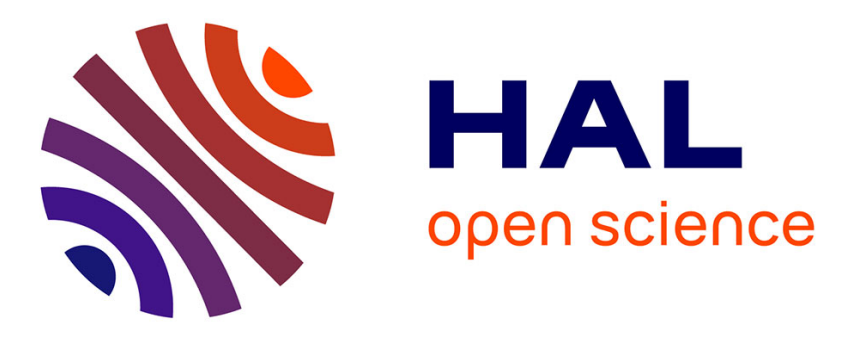

\title{
Formulation of a representative plastic strain and representative plastic strain rate by using a conical indentation on a rigid visco-plastic material
}

Liva Rabemananjara, Xavier Hernot, Gérard Mauvoisin, Adinel Gavrus, Jean-Marc Collin

\section{To cite this version:}

Liva Rabemananjara, Xavier Hernot, Gérard Mauvoisin, Adinel Gavrus, Jean-Marc Collin. Formulation of a representative plastic strain and representative plastic strain rate by using a conical indentation on a rigid visco-plastic material. Materials \& Design, 2015, 68, pp.207-214. 10.1016/j.matdes.2014.11.063 . hal-01157684

\section{HAL Id: hal-01157684 \\ https://hal.science/hal-01157684}

Submitted on 28 May 2015

HAL is a multi-disciplinary open access archive for the deposit and dissemination of scientific research documents, whether they are published or not. The documents may come from teaching and research institutions in France or abroad, or from public or private research centers.
L'archive ouverte pluridisciplinaire HAL, est destinée au dépôt et à la diffusion de documents scientifiques de niveau recherche, publiés ou non, émanant des établissements d'enseignement et de recherche français ou étrangers, des laboratoires publics ou privés. 


\title{
Formulation of a representative plastic strain and representative plastic strain rate by using a conical indentation on a rigid visco-plastic material
}

\author{
Liva RABEMANANJARA ${ }^{l}$, Xavier HERNOT ${ }^{l, 2}$, Gérard MAUVOISIN ${ }^{l, 2}$, Adinel GAVRUS ${ }^{3}$, Jean-Marc \\ COLLIN ${ }^{1,4}$ \\ ${ }^{1}$ LGCGM, Université de Rennes 1, 20 Avenue des buttes des Coësmes, 35708 Rennes Cedex 7, France \\ ${ }^{2}$ IUT, Université de Rennes 1, 3 Rue de Clos Courtel, 35700 Rennes Cedex \\ ${ }^{3}$ LGCGM, INSA de Rennes, 20 Avenue des buttes des Cö̈smes, 35708 Rennes Cedex 7, France \\ ${ }^{4}$ IUT de Nantes, 2 avenue du professeur Jean Rouxel, 44475 Carquefou Cedex \\ *Corresponding author: jean-marc.collin@univ-nantes.fr +33228032029
}

\begin{abstract}
The indentation test consists in pressing an indenter on the surface of a tested material and in measuring continually the load $\mathrm{F}$ in function of the displacement $\mathrm{h}$ of the indenter. In order to analyse the indentation curve $F(h)$ and extract material properties, one method among others uses the notion of the representative strain. The first aim of this paper is to investigate a new concept of a representative plastic strain as well as a new concept of a representative plastic strain rate. The second aim is to couple the effect of work hardening and strain rate to define the corresponding representative plastic strain and the corresponding representative plastic strain rate. We show that there are respectively two representative plastic strains and a plastic strain rate: the former obtained using the hardness of indentation and the latter obtained using the loading curve. Then, it is shown that the values of the representative strain and of the strain rate depend on the material behavior and its constitutive parameters.
\end{abstract}

Keywords: Conical indentation, representative strain, representative strain rate, finite elements

\section{Introduction}

Mechanical characterization became an important industrial challenge because of the increase of specific materials used. The instrumented indentation test (Figure 1) has been developed during the last decades and appears to be a good alternative to the classic mechanical tests to determine the mechanical properties of studied materials[1]-[4]. The indentation test is a local and quasi-non-destructive test which allows the characterization of the local and global mechanical properties when classical tests can not be used, such as in the case of a small available volume of material or in the case of a thin layer.

However, evaluating the intrinsic mechanical properties of the materials from indentation data remains a major challenge because the strain field around the indenter is heterogeneous. Then, some approaches have been proposed in order to define a 'representative strain' depending on the geometrical characteristic of the indenter and on the loading conditions [5]-[17]. In the case of a self-similar indentation of an elastic-plastic material, e.g. with a conical indenter, the geometrical similarity leads to a representative strain which does not depend on the indentation penetration degree [18]. As a consequence, by using a dimensional analysis, it is shown that during a conical indentation test both the contact hardness $H$ Equation (1) and the loading curvature $C_{L}$ Equation (2) are constant [8], [14], [18], [19]:

$H=\frac{F}{\pi a_{C}^{2}}$

$C_{L}=\frac{F}{h^{2}}$

Where $F$ is the applied load, $a_{c}$ is the contact radius and $h$ is the penetration depth of the indenter into the material. This is one of the reasons explaining why one indentation curve obtained from a conical indenter cannot lead to a unique solution in the determination of the material's mechanical properties[19]. For each set of identified parameters, which gives the same indentation loading curves, the identified stress-strain curves cross each other at a single point that corresponds to the representative strain and a representative stress, thus one point in the hardening curve can be assessed. Moreover using two kinds of indentation data, the Hardness $H$ and the curvature $C_{L}$, two separate representative strains can be assessed. They can both be used in order to identify the hardening parameters of an elastic plastic material. 
One the one hand, Tabor [5] was the first to introduce the notion of the representative strain $\varepsilon_{R P}$ obtained from the hardness estimation. He stated that the flow stress $\sigma_{R}$ is related to hardness $H$ by a confined factor $C_{F}$ defined by the following expression:

$H=C_{F} \sigma_{R}$

It has been shown that the hardness $\mathrm{H}$ of a work-hardening material increases with the angle $\theta$ of the indenter. It has also been shown that it is possible to determine the stress-strain curve of copper and mild steel metals using several angles of the cone. In his experimental study, Tabor has suggested, for a Vickers indenter, that $C_{F}=3$ and $\varepsilon_{R P}=0.08$. Using an algebraic approach similar to that used by Tabor, Chaudri [7] has proposed $\varepsilon_{R P}=0.20$ and $C_{F}=3.1$. The two authors have proposed very close values of $C_{F}$, however we can see that the proposed values of $\varepsilon_{R P}$ are very different [5], [7], [9].

On the other hand, many authors [8], [10], [11] have shown that during a conical indentation test of an elastic plastic material the curvature $C_{L}$ in equation (2) remains constant. According to the $\Pi$-theorem [18], a function of $k$ variables can be reduced on $k-p$ dimensionless variables, where $p$ is the number of fundamental units, the loading curvature $C_{L}$ can also be related to $\sigma_{R}$ with Equation (4) which leads to the determination of another representative strain [8]:

$C_{L}=\sigma_{R} \Pi_{1}\left(\frac{E^{*}}{\sigma_{R}}\right)$

Where $\Pi_{1}$ is a dimensionless function. This is the reason why the first purpose of this paper is to show that, according to the considered indentation data, the value of the representative strain is different. Moreover, this work will explain the reason of these differences.

Contrary to elastic plastic materials which were widely investigated, time dependent materials have not been investigated thoroughly. However as for the elastic plastic material, a representative strain rate $\dot{\varepsilon}_{R}$ was proposed for conical indentation of a power law creep solids[20], [21], in the aim to apply the same philosophy for a polymer[22]-[25]. According to a dimensional analysis, using a constant ratio $\frac{\dot{h}}{h}$, the geometrical similarity also occurs and both $H$ and $C_{L}$ are constant [18]. The representative strain rate $\dot{\varepsilon}_{R}$ is thus defined as proportional to the $\frac{\dot{h}}{h}$ ratio according to every author, but each gives a different formulation of this representative strain rate. For a Berkovich indenter, most of authors [26]-[28] have proposed that the representative strain rate is defined by:

$\dot{\varepsilon}_{R}=\frac{1}{h} \frac{d h}{d t}=\frac{\dot{h}}{h}$

Based on this previous work, Bucaille [29] has shown that the representative strain rate increases with $\theta$ and he has proposed the following relationship:

$\dot{\varepsilon}_{R}=0,6 \operatorname{cotan} \theta \frac{\dot{h}}{h}$

where $\theta$ is the half-angle of a conical indenter. Later, Kermouche [30] pointed out the influence of the strain rate sensitivity on the representative strain rate and stated that this latter can be approximated by:

$\dot{\varepsilon}_{R} \approx 0,44 \exp \left(\frac{0,2}{m}\right) \operatorname{cotan} \theta \frac{\dot{h}}{h}$

Regarding equation (5)-(7), different expressions of the representative strain rate, using the hardness $\mathrm{H}$, are proposed. However, the calculation of the hardness remains another problem due to the experimental measurement of the contact area for these material. Then, an alternative methodology is using the curvature $C_{L}$ of indentation for the calculation of the representative strain rate.

In this paper, we first investigated the behavior of a rigid plastic material under a conical indentation in order to define the two representative plastic strains for both $H$ and $C_{L}$. Secondly, we considered a power law creep material in order to study the influence of the strain rate parameter $m$ for both $H$ and $C_{L}$ and to suggest an explanation for the different expression of the representative strain rate. Finally, we combined the hardening 
and the sensitivity to the strain rate in order to define a representative plastic strain and a representative plastic strain rate for a rigid-viscoplastic material.

\section{Representative plastic strain and representative plastic strain rate}

\subsection{Studied materials and Finite element model}

In this section we study the concept of representative strain for a rigid plastic material, as defined by Equation 8. The concept of representative strain rate is also studied by considering, for the equivalent stress $\sigma$, a simple power law function defined by Equation 9.

$\sigma=K \varepsilon_{P}^{n}$

$\sigma=K \dot{\varepsilon}_{P}^{m}$

A numerical analysis was realized using the commercial finite element code ABAQUS in order to investigate the concepts of the representative strain and representative strain rate. A convergence investigation was performed in order to determine the optimal mesh. Moreover, the mesh near the contact zone was refined to increase the accuracy of the FE model. This latter had 6996 elements with 7158 nodes (Fig. 2). The indenter was considered as a perfectly rigid solid with $\theta=70.3^{\circ}$ (Fig. 1). The contact between the surface of the indenter and the specimen was modeled using a friction Coulomb model with $\mu=0.1$. The kinematic condition of the penetration was performed respecting $\frac{\dot{h}}{h}=5.585 \mathrm{~s}^{-1}$, which corresponds to the value used by Kermouche [30]. The rheological parameters used in this study are presented in Table 1. The high values of the Young's modulus $E$ and the consistency $K$ were chosen to simulate rigid plastic properties. The material behavior was considered as an isotropic hardening flow defined by the Von Mises criteria.

\subsection{Representative plastic strain}

In order to introduce the concept of representative plastic strain, a rigid plastic material governed by Equation 8 is considered. As stated in the introduction, two indentation data, with two indenters, can be used in order to determine two different representative strains.

\subsubsection{Representative plastic strain obtained using the contact Hardness}

Combining the Tabor Equation 3 and the considered behavior law Equation 8 leads to the following relationships:

$\frac{H}{K}=C_{F} \varepsilon_{R P}^{n}$

Then

$\ln \left(\frac{H}{K}\right)=n \ln \varepsilon_{R P}+\ln C_{F}$

According to Equation 11, $\ln \left(\frac{H}{K}\right)$ linearly depends on $n$ if the $\varepsilon_{R P}$ and $C_{F}$ are constant. Figure 3 illustrates that concerning the Tabor results, the linearity is verified which leads to a constant value of representative plastic strain during a conical indentation test. In the present study, it is shown that the linearity is not verified for every value of the hardening parameter $n$. However, we assume local linearities, which leads to a new expression of a representative plastic strain as a function of the hardening parameter and defined by the slope of the $\ln \left(\frac{H}{K}\right)$ to $n$ :

$\frac{\partial}{\partial n} \ln \left(\frac{H}{K}\right)=\ln \varepsilon_{R P}$

Then, 
$\varepsilon_{R P}=\exp \left[\frac{\partial}{\partial n}\left(\ln \left(\frac{H}{K}\right)\right)\right]=\exp \left(\frac{\partial}{\partial n}(\ln (H))\right)$

In Figure 3, it is shown that for $n$ with a value lower than 0.15 , the slope of these numerical results are in good correlation to the slope of the experimental results found by Chaudri [7] and for a value of $n$ higher than 0.2 it is equal to the experimental results found by Tabor [5]. Moreover, Figure 4 shows the representative plastic strain calculated by using the mean pressure for each value of the hardening parameter $n$. This result was obtained for a rigid plastic material and it illustrates that the value of representative plastic strain depends on the material properties contrary to the philosophy introduced by Tabor and Chaudri. According to this result, the representative strain assessed by Chaudri corresponds to the low values of $n$ and that of Tabor's corresponds to the values of $n$ which are between 0.28 and 0.38 . Fig (3) illustrates that the present model allows the determination of the changes of the plastic representative strain for all the values of $n$. Moreover, this result is in accordance with the literature, the plastic representative strain varies between the Tabor value for low values of $n$ and decreases to the Chaudri values for high values of $n$.

\subsubsection{Representative plastic strain obtained using the loading curve}

The determination of the contact area and then the hardness is still an important challenge for experimental indentation studies. This is the reason why the most common used data is the load-depth curve. As explained previously, during a conical indention test of a rigid-plastic material the curvature of the loading curve is constant. According to Equation 4 and by following the same approach as in the former section, we obtain:

$\ln \left(\frac{C_{L}}{K}\right)=n \ln \varepsilon_{R P}+\ln \Pi_{1}\left(\frac{E^{*}}{\sigma_{R}}, \theta\right)$

Thus, we can also define the representative plastic strain by using the curvature of a loading curve:

$\varepsilon_{R P}=\exp \left[\frac{\partial}{\partial n}\left(\ln \left(\frac{C_{L}}{K}\right)\right)\right]=\exp \left[\frac{\partial}{\partial n}\left(\ln \left(C_{L}\right)\right)\right]$

\subsection{Representative plastic strain rate}

For an isotropic solid during the steady-state creep regime, the stress can be defined by using the power law function of strain rate described in Equation 9.

\subsubsection{Geometrical similarity on the time-dependent material during a conical indentation}

By applying the $\Pi$-theorem, Cheng and Cheng [18], have proposed the following relationships:

$F=K\left(\frac{\dot{h}}{h}\right)^{m} \Pi_{\alpha}(m, \theta) h^{2}$

$A_{C}=h^{2} \Pi_{\beta}(m, \theta)$

where $\Pi_{\alpha}$ and $\Pi_{\beta}$ are dimensionless functions, $\dot{h}$ is the penetration rate of indenter. The mean pressure is defined by:

$H=K\left(\frac{\dot{h}}{h}\right)^{m} \Pi_{\gamma}(m, \theta)$

where $\Pi_{\gamma}=\frac{\Pi_{\alpha}}{\Pi_{\beta}}$ is a dimensionless function. Equations 16 and 18 show that if the ratio $\frac{\dot{h}}{h}$ is constant during the indentation test, both the proportionality of the load to the square of the displacement and the constant hardness are verified. In Figure 5, a numerical simulation of the indentation test controlled by a constant displacement rate shows that the mean pressure is different during penetration. However for the kinematic condition $\frac{\dot{h}}{h}$ constant, the distribution of the mean pressure is the same for all values of $h$. Then the similarity of 
indentation is still correct. Consequently, the relationships proposed in the previous section can be applied. The representative strain can be respectively related to the mean pressure and to the curvature of the loading curve. In the following sections, the representative strain rate is obtained from these two pieces of data.

\subsubsection{Representative plastic strain rate obtained using the contact hardness}

Respecting Tabor's suggestion, who states that the representative stress can be related to the hardness by the constrain factor, and combining Equations 9 and 18, we can write:

$H=K C_{F} \dot{\varepsilon}_{P}^{m}$

Then

$\ln \left(\frac{H}{K\left(\frac{\dot{h}}{h}\right)^{m}}\right)=m \ln \chi+\ln C_{F}$

where $\chi=\frac{\dot{\varepsilon}_{R P}}{\left(\frac{\grave{h}}{h}\right)}$. According to Equation 20, the logarithm of the mean pressure linearly depends on the strain rate sensitivity $m$ if $\chi$ is constant. However, Figure 6 illustrates that this is not verified for the high values of $m$. In similitude to the previous reasoning we can assume a local linearity. We can thus define the first expression of the representative plastic strain rate obtained by using the mean pressure:

$\dot{\varepsilon}_{R P}=\frac{\dot{h}}{h} \exp \left\{\frac{\partial}{\partial m} \ln \left[\frac{H}{K\left(\frac{\dot{h}}{h}\right)^{m}}\right]\right\}$

The above expression shows that the representative plastic strain rate is proportional to the ratio of the indenter's displacement speed and the displacement. This relationship has been also confirmed by Bucaille [29] and Kermouche [30] in their work that stated that the representative strain rate was strongly related to the half angle of the indenter.

The results obtained by considering a creep power law is presented in Figure 7 and it illustrates that the representative strain rate depends on the value of the strain rate sensitivity $m$ which was previously observed by Kermouche [30]. For $m$ higher than 0.12 , the ratio of the representative plastic strain rate to $\frac{\dot{h}}{h}$ correlates with the results obtained by Kermouche, however for the lower values of $m$ the present model allows us to determine a representative strain rate even if $m$ is equal to 0 . We can also notice that the value proposed by Bucaille [29] is correct for a value of $m$ close to 0.08. As a conclusion, as for the representative strain, the representative strain rate proposed in this paper is in accordance with the literature results. The proposed formulation allows having a changes of the representative strain rate for the whole $n$ values. The values are very close to the one proposed by Kermouche [30] for the high values of $n$ and the results of Bucaille [29] represent a middle constant value of this representative strain rate whatever $n$.

\subsubsection{Representative plastic strain rate obtained using the loading curve}

Concerning the use of the curvature, Equations 2, 9 and 16 lead to

$\ln \left[\frac{C_{L}}{K\left(\frac{\dot{h}}{h}\right)^{m}}\right]=m \ln \chi+\ln \left(\Pi_{\alpha}\right)$

Then the representative plastic strain rate obtained by using the loading curve can be expressed as: 
$\dot{\varepsilon}_{R P}=\frac{\dot{h}}{h} \exp \left\{\frac{\partial}{\partial m} \ln \left[\frac{C_{L}}{K\left(\frac{\dot{h}}{h}\right)^{m}}\right]\right\}$

\section{Study of a rigid visco-plastic material}

\subsection{Combining hardening and strain rate sensitivity effect}

In this section, we will consider a rigid visco-plastic material governed by a power law, defined as

$\sigma=K \varepsilon_{P}^{n} \dot{\varepsilon}_{P}^{m}$

The load during indentation test can be expressed as a function of material parameters, the penetration of indenter $h$, the rate of penetration $\dot{h}$, the Poisson's ratio $v$, the friction's coefficient $\mu$ and the half angle of the indenter $\theta$.

$F=f(K, m, n, h, \dot{h}, v, \mu, \theta)$

According to dimensional analysis, assuming that the Poisson's ratio $v$ and the friction's coefficient $\mu$ are known, we can write:

$F=K\left(\frac{\dot{h}}{h}\right)^{m} \Pi_{\alpha}(m, n, \theta) h^{2}$

$A_{C}=h^{2} \Pi_{\beta}(m, n, \theta)$

Then, the hardness can be defined by:

$$
H=K\left(\frac{\dot{h}}{h}\right)^{m} \Pi_{\gamma}(m, n, \theta)
$$

Combining Equation 3, 4, 27 and 29 leads to:

$\ln \left[\frac{\left(H \text { or } C_{L}\right)}{K\left(\frac{\grave{h}}{h}\right)^{m}}\right]=m \ln (\chi)+n \ln \left(\varepsilon_{P}\right)+\ln \left(C_{F}\right.$ or $\left.\Pi_{1}\right)$

According to Equation 30 we can notice that if both the representative plastic strain and $\chi$ are constant, isovalues of the logarithm of the mean pressure or the curvature depend linearly on the hardening parameter $n$ and the strain rate sensitivity $m$. However, the results of the numerical analysis show that the linear distribution is not verified (Figure 8).

Then for a first approximation, we will consider a set of parallelogram where the linearity is locally verified and the following relationship is valid at each apex of this parallelogram:

$\ln \left[\frac{H_{i} \text { or } C_{L i}}{K_{i}\left(\frac{\grave{h}}{h}\right)^{m_{i}}}\right]=m_{i} \alpha+n_{i} \beta+\gamma$

where $i=1$ to 4 , this represents the index of the parallelogram's apex.

Thus, the representative plastic strain and the representative plastic strain rate can be deduced by determining for each element the value of coefficients $\alpha, \beta$ and $\gamma$. 


\subsection{Results obtained using the mean pressure}

The value of the representative plastic strain and $\chi$ functions depending on $n$ and $m$, obtained by considering the mean pressure, are represented in Figure 9 . It is shown that, for each set of $(m, n)$ there exist well-defined values of representative plastic strain and representative plastic strain rate. According to these numerical results, several observations can be made. First of all, for values of $m$ and $n$ higher than 0.15 the representative plastic strain and $\chi$ remain almost constant and very low. We can thus conclude that, in this domain, the representative strains proposed by Tabor [5] and Chaudri [7] are verified. This observation can also be extended to the representative strain rate. However, for values of $m$ and $n$ smaller than 0.15 , the representative plastic strain increases from $12 \%$ to $25 \%$ and $\chi$ increases from 0.2 to 0.8 . This illustrates that there is not a single value for the representative strain and the representative strain rate for all values of $m$ and $n$. The fact that the representative strain and the representative strain rate are not constant in the $n-m$ space demonstrates that using one conical indenter and one value of $\frac{\dot{h}}{h}$ cannot lead to a unique point of the stress strain curve. Moreover, it is important to notice that when $m$ is close to 0 , which corresponds to a large class of materials, a representative plastic strain rate can be determined from the present method. This was not possible using the previous model proposed by Kermouche [30]. As illustrated before, the present paper propose formulations in accordance with the literature results but allowing to have access to the changes of the representative strain and strain rate in the whole $m$ and $n$ space.

\subsection{Results obtained by using the curvature of the loading curve}

The curvature of the loading curve can easily be obtained experimentally, contrary to the mean pressure. Figure 10 shows the representative plastic strain and the representative plastic strain rate as functions of the material parameters $m$ and $n$. This result reveals that the representative strain is lower than that obtained from the mean pressure. When $m$ is equal to 0 , which is the case of a material insensitive to the strain rate, the representative strain varies between $2.8 \%$ and $4.5 \%$.

\section{Conclusions}

In this paper we used a conical indenter in order to propose new formulations of the representative plastic strain and the representative plastic strain rate for a rigid viscoplastic material. Contrary to the theory which stated that the representative strain induced by a conical indenter is constant, whatever the studied material, it is shown in this paper that this data depends strongly on the mechanical properties. It is also shown that the use of the mean pressure or the loading curve of indentation give different values for the representative strain as well as for the representative strain rate. Concerning the representative strain rate, this investigation is in accordance with the literature that states that the representative strain rate induced by a conical indentation is proportional to the ration $\frac{h}{h}$. However, the representative plastic strain and representative plastic strain rate assessed in this paper was obtained using an indenter with a half angle equal to $70.3^{\circ}$. Thus it would be interesting to extend this study for several different half angles of indenter but the friction effect which cannot be neglected must be studied for lower values of the conical indenter's angle.

\section{References}

[1] Blau PJ, Lawn BR. Microindentation Techniques in Materials Science and Engineering 1985 15-18.

[2] Alcalà J, Giannakopoulos AE, Suresh S. Continuous measurements of load-penetration curves with spherical microindenters and the estimation of mechanical properties. J Mater Res 1998; 13: $1390-1400$.

[3] Collin JM., Mauvoisin G, Pilvin P. Materials characterization by instrumented indentation using two different approaches. Mater Des 2010; 31: 636-640.

[4] Li W, Huang C, Yu M, Liao H. Investigation on mechanical property of annealed copper particles and cold sprayed copper coating by a micro-indentation testing. Mater Des 2013; 46: 219-226. 
[5] Atkins AG, Tabor D. Plastic indentation in metals with cones. J Mech Phys Solids 1965; 13: 149-164.

[6] Giannakopoulos AE, Suresh S. Determination of elastoplastic properties by instrumented sharp indentation. Scr Mater 1999; 40: 1191-1198.

[7] Chaudhri MM. Subsurface strain distribution around Vickers hardness indentations in annealed polycrystalline copper. Acta Mater 1998; 46: 3047-3056.

[8] Dao M, Chollacoop N, Van Vliet KJ, Venkatesh T A, Suresh S. Computational modeling of the forward and reverse problems in instrumented sharp indentation. Acta Mater 2001; 49: 3899-3918.

[9] Larsson PL. Investigation of sharp contact at rigid-plastic conditions. Int J Mech Sci 2001;43: 895-920.

[10] Bucaille JL, Stauss S, Felder E, Michler J. Determination of plastic properties of metals by instrumented indentation using different sharp indenters. Acta Mater 2003; 51: 1663-1678.

[11] Chollacoop N, Dao M, Suresh S. Depth-sensing instrumented indentation with dual sharp indenters. Acta Mater 2003; 51: 3713-3729.

[12] Ogasawara N, Chiba N, Chen X. Representative Strain of Indentation Analysis. J Mater Res 2005; 20: 2225-2234.

[13] Chollacoop N, Ramamurty U. Experimental assessment of the representative strains in instrumented sharp indentation. Scr Mater; 53: 247-251.

[14] Kermouche G, Loubet JL, Bergheau JM. An approximate solution to the problem of cone or wedge indentation of elastoplastic solids. Comptes Rendus Mécanique 2005; 333: 389-395.

[15] Cao Y, Huber N. Further investigation on the definition of the representative strain in conical indentation. J Mater Res 2006; 21: 1810-1821.

[16] Fu K, Chang L, Zheng B, Tang Y, Wang H. On the determination of representative stress-strain relation of metallic materials using instrumented indentation. Mater Des 2015; 65: 989-994.

[17] Hernot X, Moussa C, Bartier O. Study of the concept of representative strain and constraint factor introduced by Vickers indentation. Mech Mater 2014; 68: 1-14.

[18] Cheng YT, Cheng CM. Scaling, dimensional analysis, and indentation measurements. Mater Sci Eng R Rep 2004; 44: 91-149.

[19] Cheng YT, Cheng CM. Can stress-strain relationships be obtained from indentation curves using conical and pyramidal indenters? J Mater Res 1999; 14: 3493-3496.

[20] Takagi H, Dao M, Fujiwara. Analysis on pseudo-steady indentation creep. Acta Mech Sol. 2008 ;21: 283-288.

[21] I.-C. Choi, B.-G. Yoo, Y.-J. Kim, et J. Jang, « Indentation creep revisited », J. Mater. Res., vol. 27, nº 01, p. 3-11, janv. 2012.

[22] B. J. Briscoe et K. S. Sebastian, « The Elastoplastic Response of Poly(Methyl Methacrylate) to Indentation ", Proc. R. Soc. Math. Phys. Eng. Sci., vol. 452, n 1946, p. 439-457, mars 1996.

[23] B. J. Briscoe, L. Fiori, et E. Pelillo, « Nano-indentation of polymeric surfaces ", J Phys Appl Phys, vol. 31, p. 2395-2405, 1998.

[24] M. L. Oyen et R. F. Cook, « Load-displacement behavior during sharp indentation of viscouselastic-plastic materials ", J. Mater. Res., vol. 18, nº 01, p. 139-150, janv. 2003.

[25] J. Giró-Paloma, J. J. Roa, A. M. Díez-Pascual, E. Rayón, A. Flores, M. Martínez, J. M. Chimenos, et A. I. Fernández, « Depth-sensing indentation applied to polymers: A comparison between standard methods of analysis in relation to the nature of the materials ", Eur. Polym. J., vol. 49, $\mathrm{n}^{\circ}$ 12, p. 4047-4053, déc. 2013.

[26] M. J. Mayo et W. D. Nix, " A micro-indentation study of superplasticity in Pb, Sn, and Sn-38 wt\% $\mathrm{Pb}$ », Acta Metall., vol. 36, nº 8, p. 2183-2192, août 1988.

[27] B. N. Lucas, W. C. Oliver, G. M. Pharr, et J.-L. Loubet, « Time Dependent Deformation During Indentation Testing ", MRS Proc., vol. 436, janv. 1996. 
[28] P. Bertrand-Lambotte, J. . Loubet, C. Verpy, et S. Pavan, "Nano-indentation, scratching and atomic force microscopy for evaluating the mar resistance of automotive clearcoats: study of the ductile scratches ", Proc. 28th Int. Conf. Metall. Coat. Thin Films, vol. 398-399, n 0, p. 306-312, nov. 2001.

[29] J. L. Bucaille, E. Felder, et G. Hochstetter, « Identification of the viscoplastic behavior of a polycarbonate based on experiments and numerical modeling of the nano-indentation test " $J$. Mater. Sci., vol. 37, n 18, p. 3999-4011, sept. 2002.

[30] G. Kermouche, J. L. Loubet, et J. M. Bergheau, " Extraction of stress-strain curves of elasticviscoplastic solids using conical/pyramidal indentation testing with application to polymers ", Mech. Mater., vol. 40, $n^{\circ}$ 4-5, p. 271-283, avr. 2008. 


\section{List of captions}

Table 1: Rheological parameters used in this study (v represent the Poisson's ratio)

Figure 1: Illustration of an instrumented indentation test (a) Conical indenter where $h$ is the penetration depth, $a_{c}$ is the contact radius and $h_{c}$ is the contact depth; (b) Loading curve obtained by using a conical indenter

Figure 2: Finite element mesh with an axisymmetric model

Figure 3: Values of $\ln \left(\frac{H}{K}\right)$ function of hardening parameter. (.) Results obtained by this numerical analysis; (-) Experimental results found by Tabor; (--) Experimental results found by Chaudri

Figure 4: Variation of the representative plastic strain function of the hardening parameter

Figure 5: Mean pressure function of the contact depth $h_{c}$ : (a) obtained for a numerical simulation of indentation test with penetration rate constant; (b) obtained for a numerical simulation with $\frac{\dot{h}}{h}$ constant (where $a_{c}$ is the contact radius)

Figure 6: Values of : (a) $\ln \left[\frac{C_{L}}{K\left(\frac{h}{h}\right)^{m}}\right]$ functions of the strain rate sensitivities (.)Numerical results, (-) Linear approximation; (b) $\ln \left[\frac{H}{K\left(\frac{h}{h}\right)^{m}}\right]$ functions of the strain rate sensitivities (.)Numerical results, (-) Linear approximation obtained by considering constant $\frac{\dot{h}}{h}$ during the numerical simulation

Figure 7: Value of the ratio $\frac{\dot{\varepsilon}_{R P}}{\frac{h}{h}}$ function of the strain rate sensitivity m

Figure 8: Relationship between: (a) $\ln \left[\frac{H}{K\left(\frac{\dot{h}}{h}\right)^{m}}\right]$, (b) $\ln \left[\frac{\mathrm{C}_{\mathrm{L}}}{\mathrm{K}\left(\frac{\dot{\mathrm{h}}}{\mathrm{h}}\right)^{\mathrm{m}}}\right]$ to the hardening parameter $n$ and strain rate sensitivities $m$, showing that there is no linear dependency

Figure 9: Mapping of (a) the representative plastic strain (b) the ratio of the representative plastic strain rate and $\frac{\dot{h}}{h}$ both obtained by considering the mean pressure of indentation

Figure 10: Mapping of (a) the representative plastic strain (b) the ratio of the representative plastic strain rate, both obtained by considering the curvature of indentation loading 
Table 2

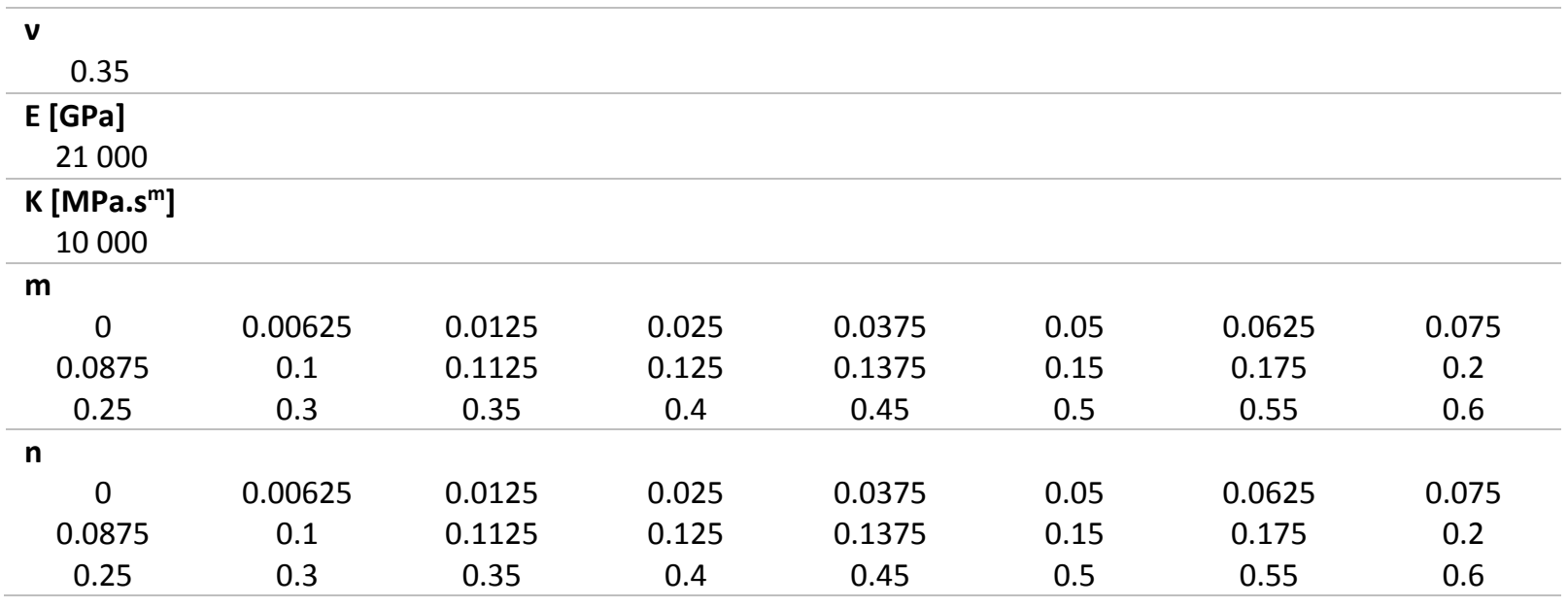


Figure 1

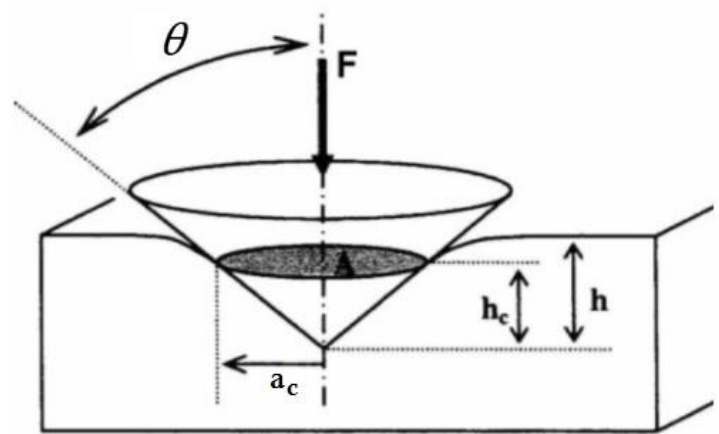

(a)

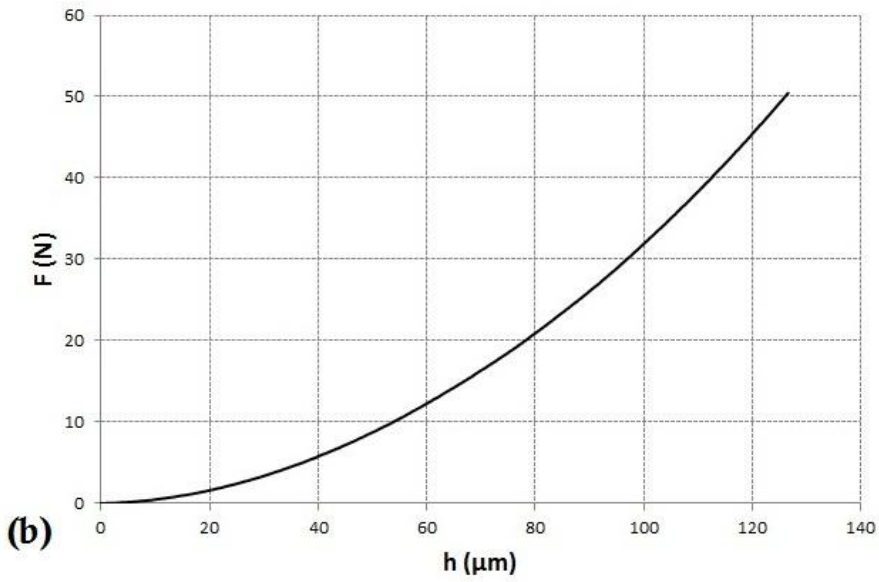


Figure 2

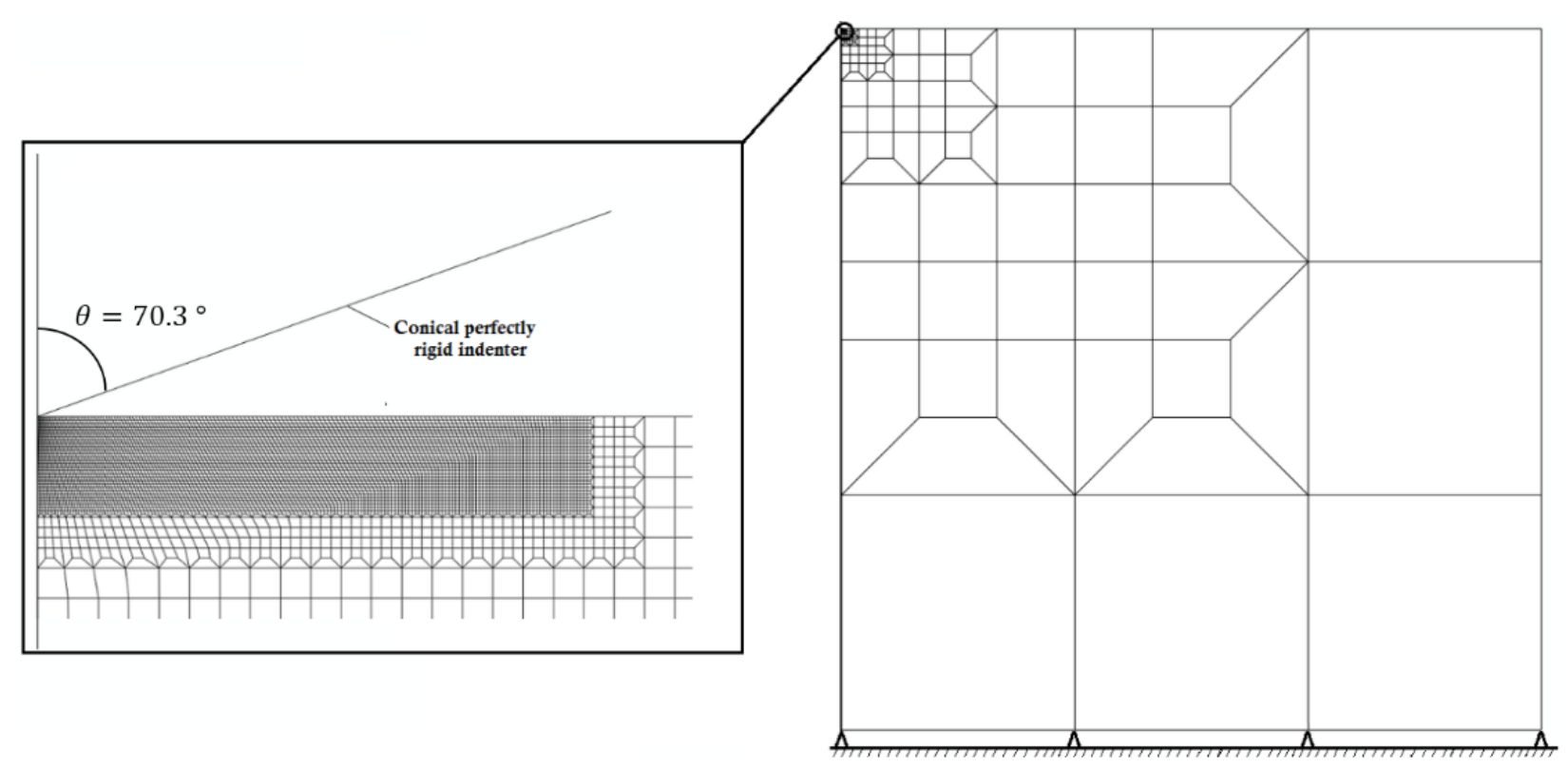


Figure 3

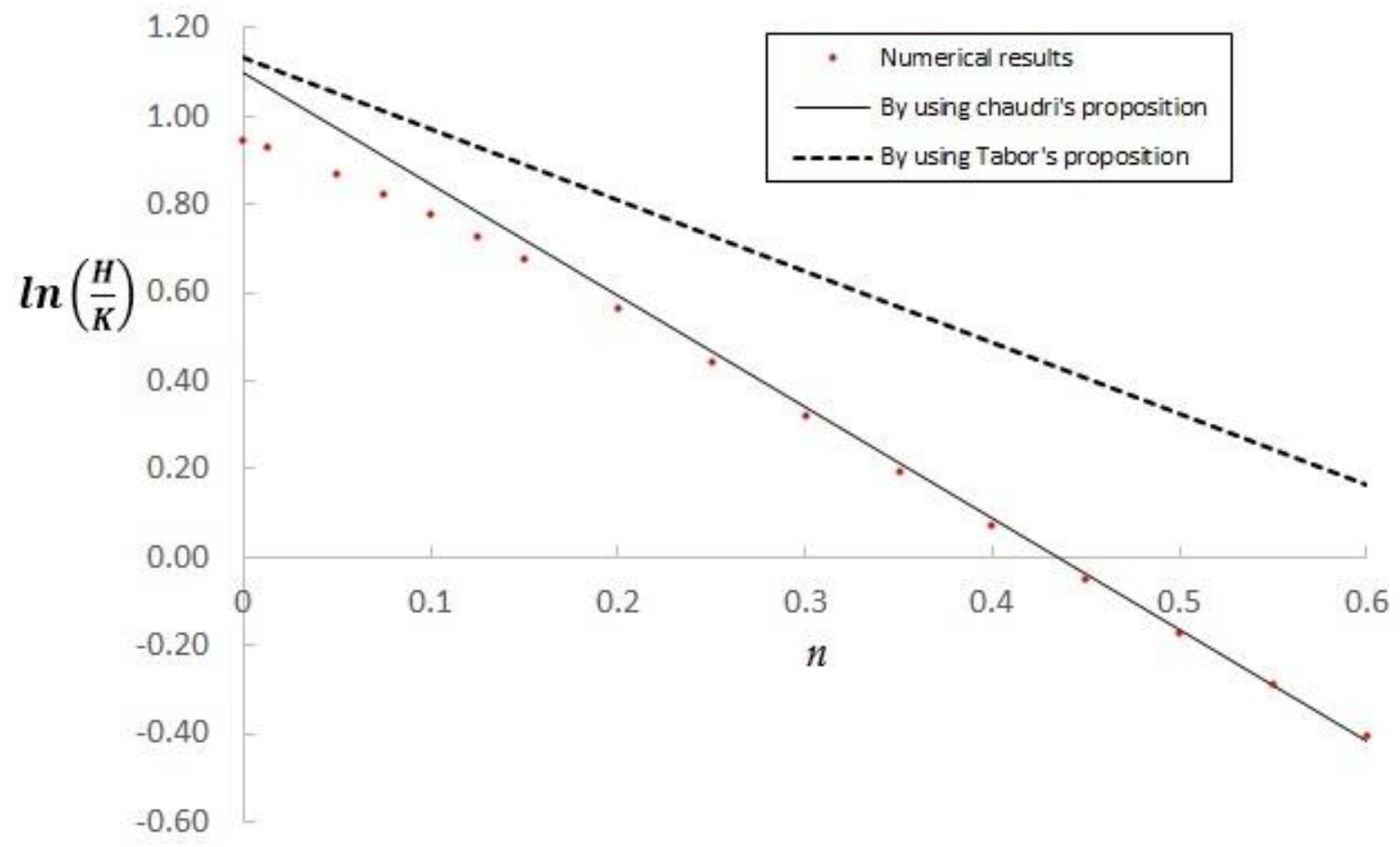


Figure 4

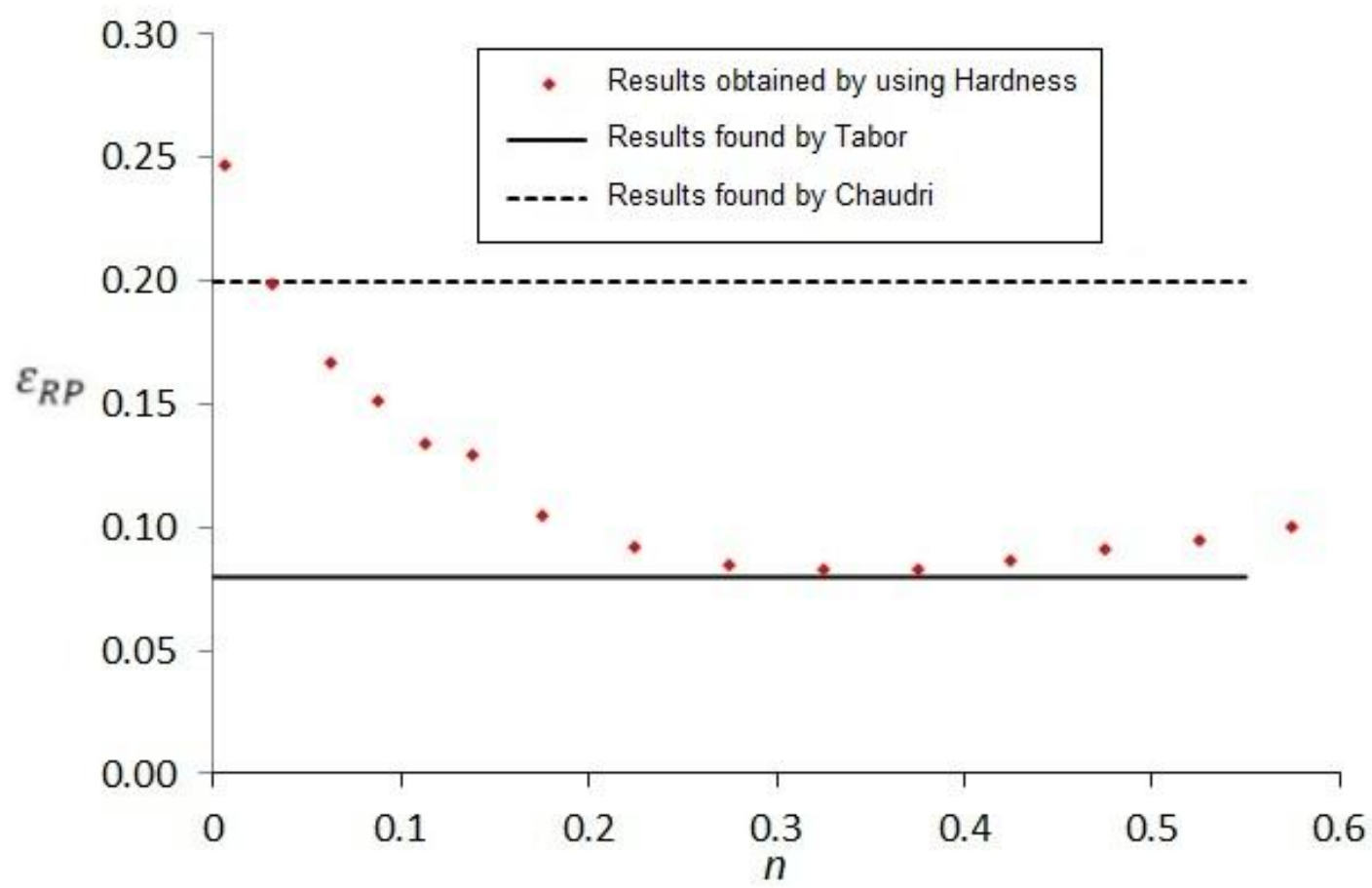




\section{Figure 5}
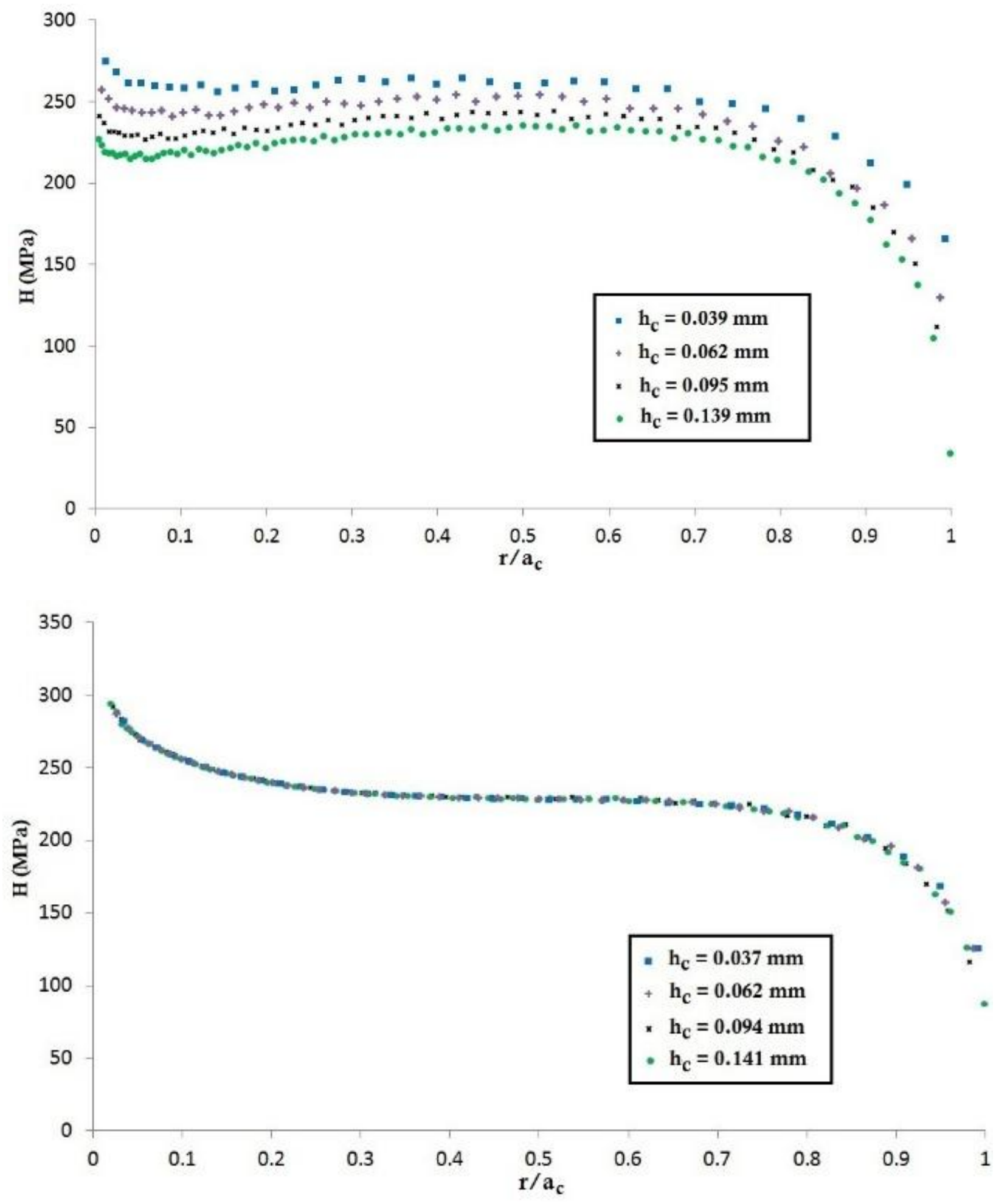
Figure 6

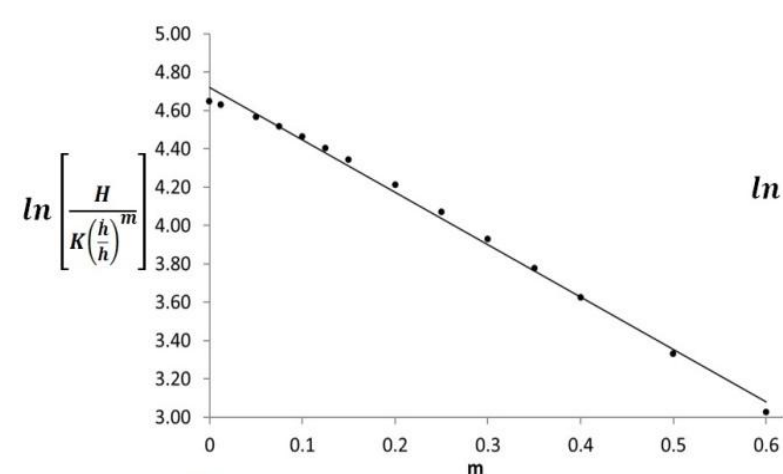

(a)

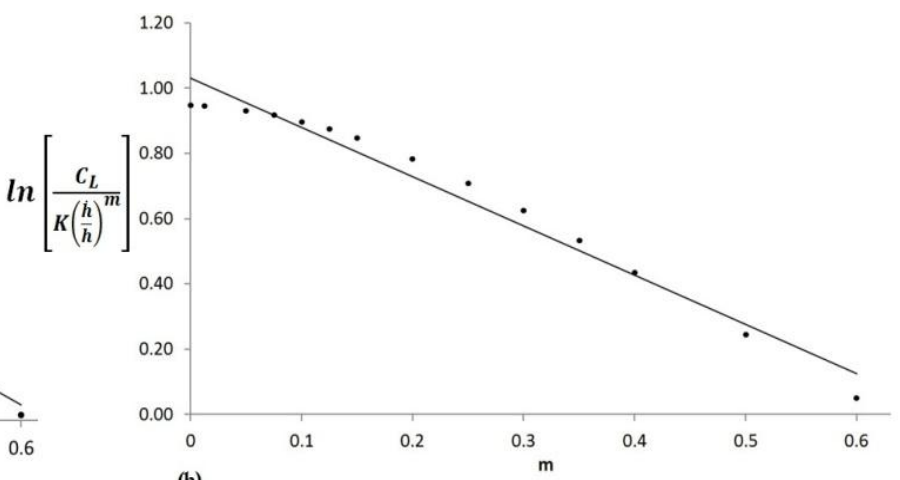

(b) 
Figure 7

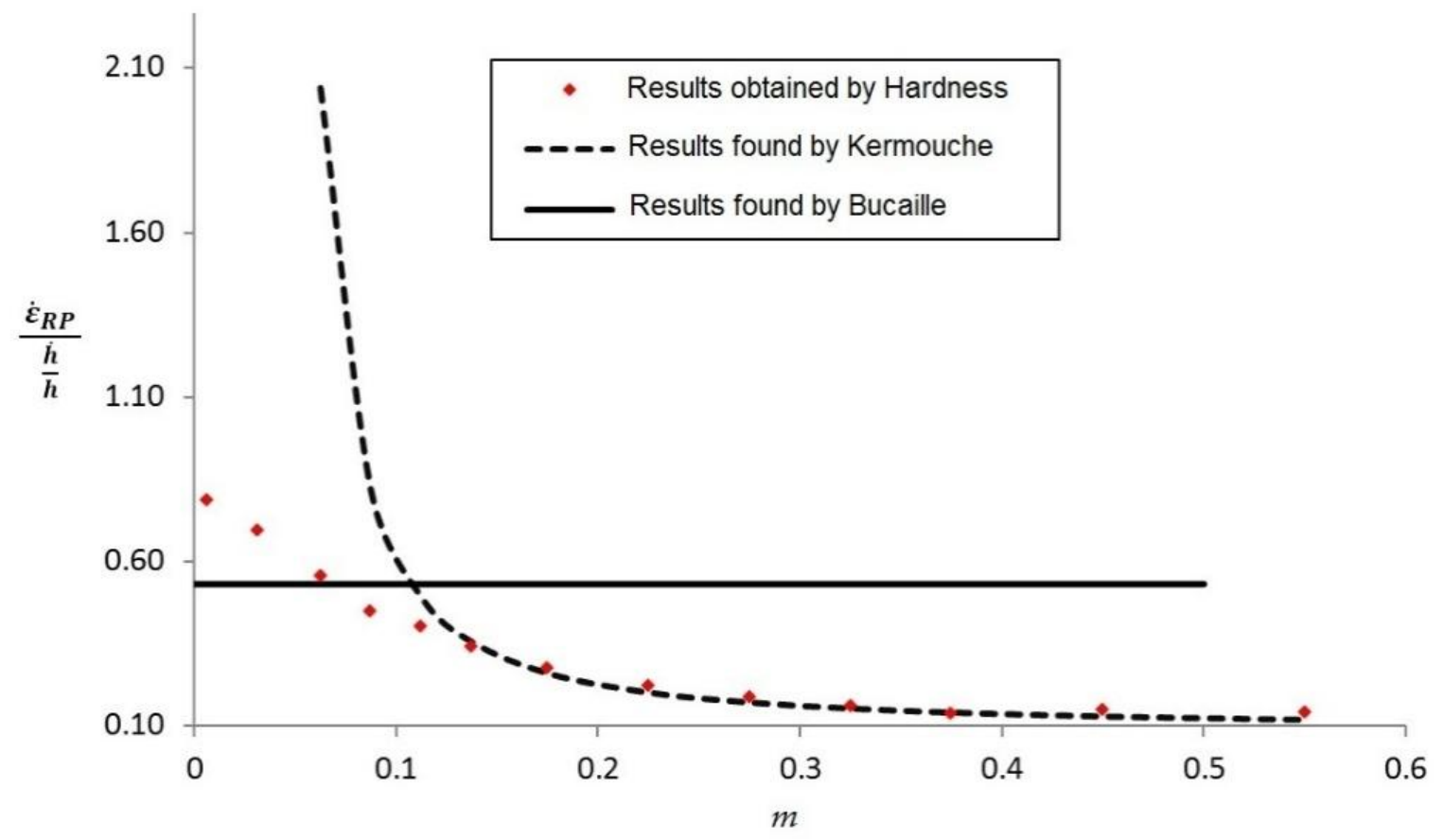


Figure 8
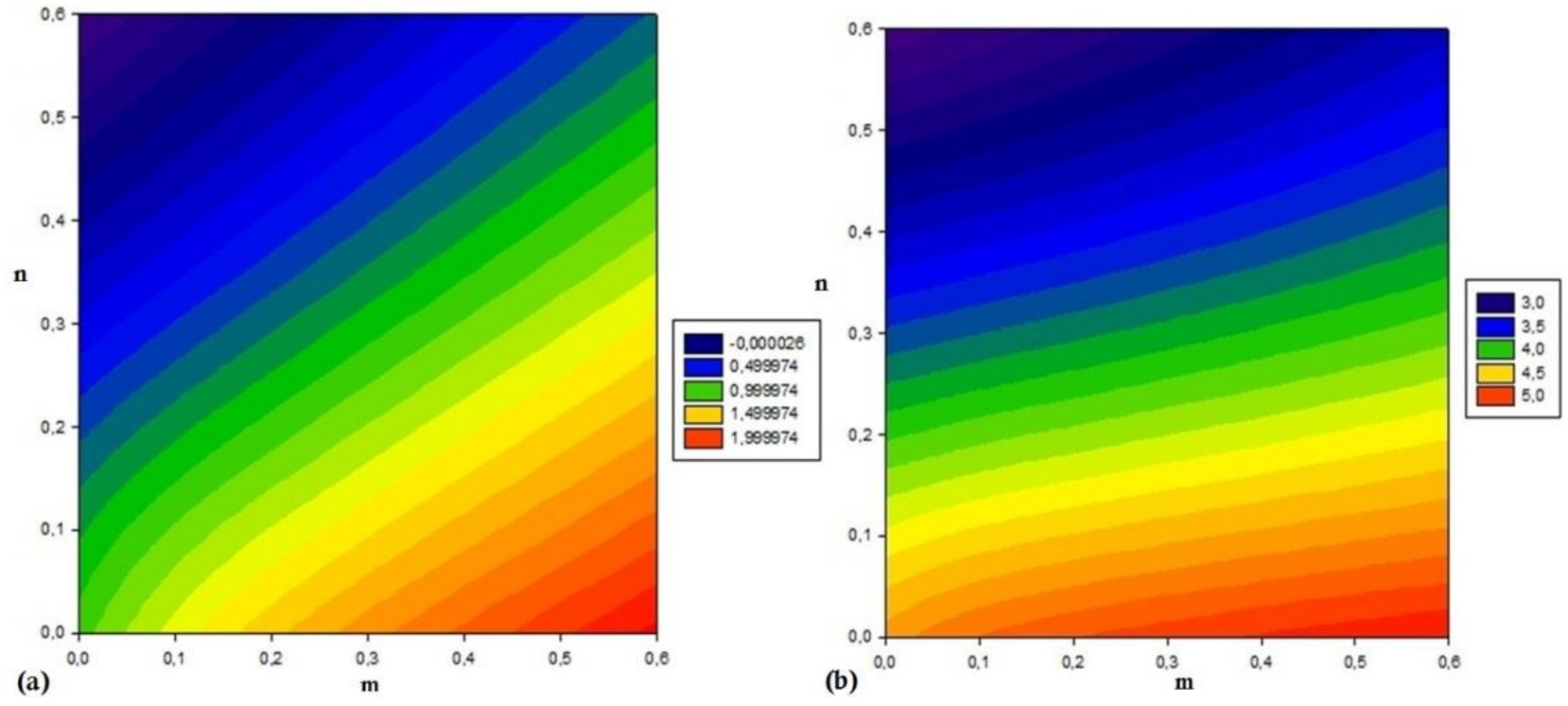
Figure 9

(a)

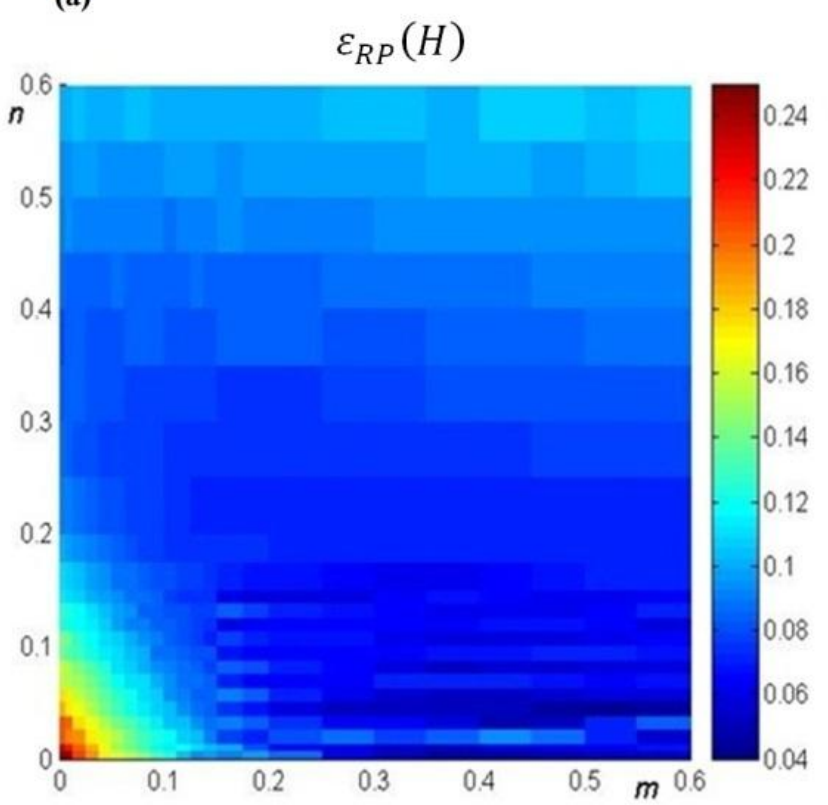

(b) $\quad \frac{\dot{\varepsilon}_{R}}{\left(\frac{\dot{h}}{h}\right)}(H)$

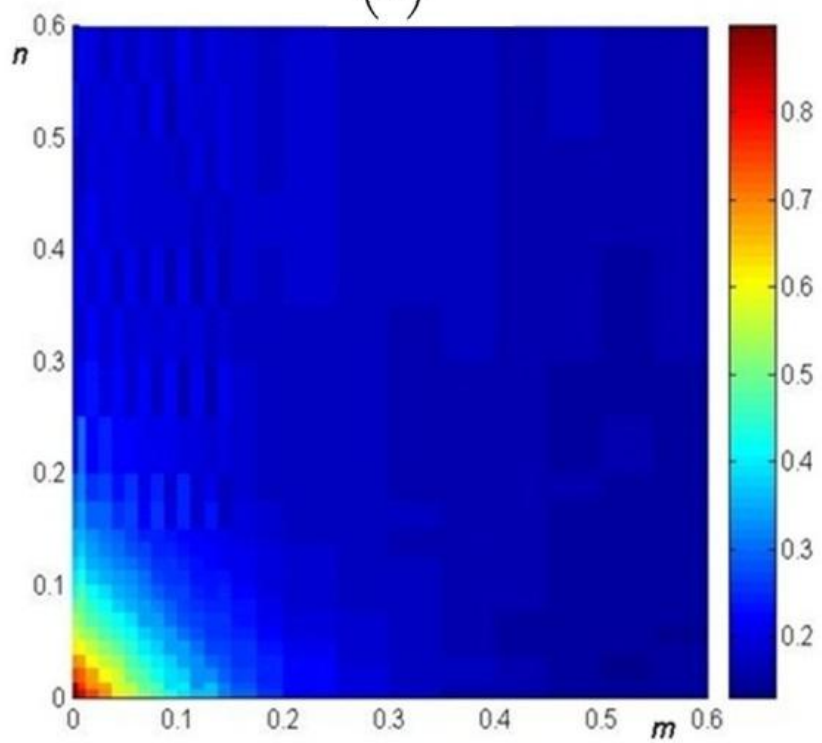


Figure 10

(a)

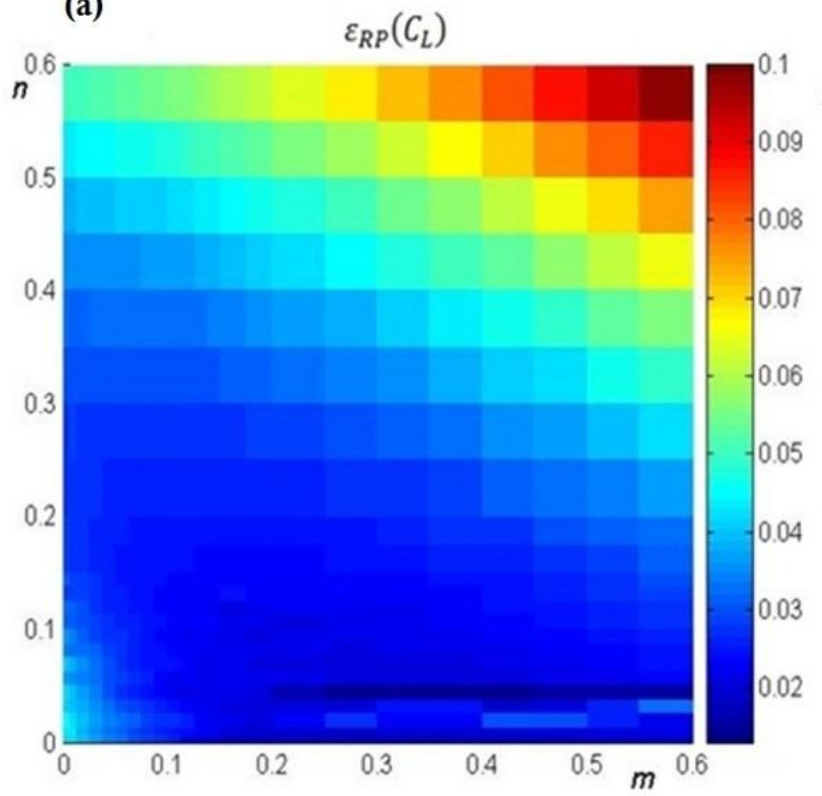

(b)

$\frac{\varepsilon_{R}}{\left(\frac{h}{h}\right)}\left(C_{L}\right)$

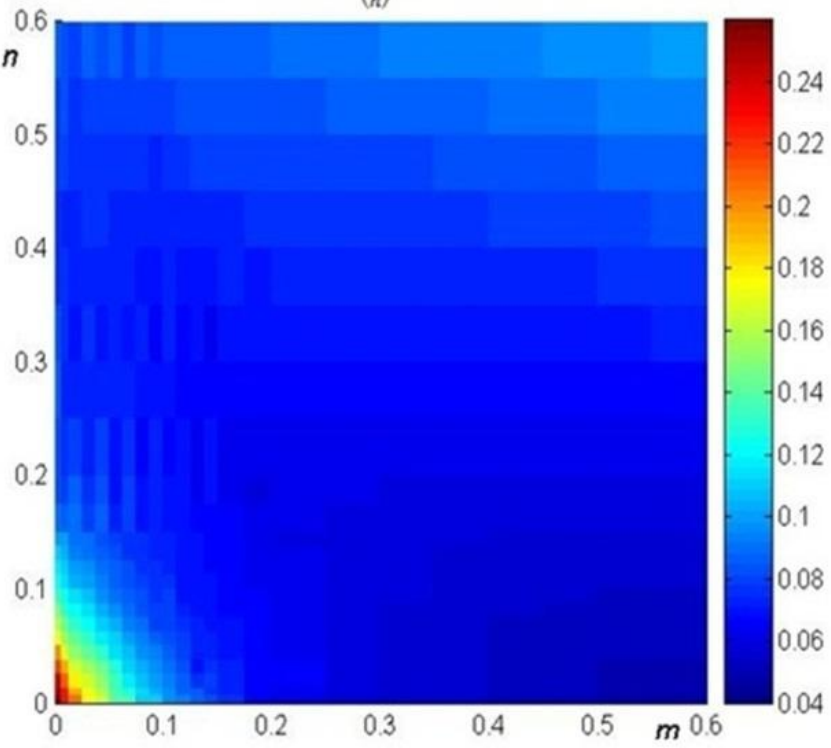

